Relations industrielles

Industrial Relations

\title{
La négociation collective en France, par Gérard Adam, Jean-Daniel Reynaud et Jean-Maurice Verdier, collection "Relations sociales ». Paris, Editions Économie et Humanisme - Les Éditions Ouvrières, 1972, 126 pp.
}

\section{Gérard Dion}

Volume 27, numéro 4, 1972

URI : https://id.erudit.org/iderudit/028359ar

DOI : https://doi.org/10.7202/028359ar

Aller au sommaire du numéro

\section{Éditeur(s)}

Département des relations industrielles de l'Université Laval

ISSN

0034-379X (imprimé)

1703-8138 (numérique)

Découvrir la revue

Citer ce compte rendu

Dion, G. (1972). Compte rendu de [La négociation collective en France, par Gérard Adam, Jean-Daniel Reynaud et Jean-Maurice Verdier, collection « Relations sociales ». Paris, Editions Économie et Humanisme - Les Éditions Ouvrières, 1972, 126 pp.] Relations industrielles / Industrial Relations, 27(4), 806-806. https://doi.org/10.7202/028359ar

Tous droits réservés (C Département des relations industrielles de l'Université Laval, 1972
Ce document est protégé par la loi sur le droit d'auteur. L'utilisation des services d'Érudit (y compris la reproduction) est assujettie à sa politique d'utilisation que vous pouvez consulter en ligne.

https://apropos.erudit.org/fr/usagers/politique-dutilisation/ 
n'a pas rempli sa mission qui devait être d'établir le dialogue entre chercheurs et administrateurs. Les politiques actuelles en matière d'enseignement universitaire sont loin d'être sans reproche et les économistes ont plus de suggestions pertinentes à proposer que ne le révèle cette publication.

\section{Gérard BELANGER}

La négociation collective en France, par Gérard Adam, Jean-Daniel Reynaud et Jean-Maurice Verdier, collection 《Relations sociales ». Paris, Editions Economie et Humanisme - Les Editions Ouvrières, 1972, 126 pp.

Cette brève étude a été rédigée pour servir de rapport introductif à un colloque tenu à Paris en 1971. Les auteurs n'ont pas cherché à faire toute l'histoire de la négociation collective en France ni à présenter une revue complète et minutieuse des faits. Ils ont plutôt tenté de faire un bilan de la situation en relevant ce qui paraissant de plus important dans le passé récent et en mettant en valeur quelques développements prometteurs et quelques lacunes majeures.

L'ouvrage est divisé en deux parties. Dans la première, consacrée aux tendances nouvelles, on y trouve : la reconnaissance de la négociation, les accords interprofessionnels, le progrès de la négociation de branche, la radicalisation et la négociation dans le secteur public. Dans la seconde, sous le titre de problèmes et perspectives, on $y$ envisage : le rôle des pouvoirs publics dans les négociations collectives, le cadre et le niveau des négociations, l'appareil et la masse, la négociation permanente. Enfin, une série d'annexes fournissant différentes statistiques et des documents.

Le lecteur qui n'était pas déjà familier avec le régime des relations professionnelles en France et son fonctionnement constatera que la véritable négociation collective en ce pays est un phénomène assez récent et qu'elle cherche sa voie au milieu de nombreuses difficultés. Une conception du rôle de l'Etat ainsi que les traditions, les attitudes et les orientations des partenaires sociaux n'ont pas facilité l'implantation de la négociation collective. Des progrès considérables ont été marqués en ces dernières années. Cependant, tenant compte des institutions françaises il est illusoire d'aller chercher des modèles à l'étranger, surtout en Amérique du Nord.

Les auteurs ont bien exposé les difficultés d'articuler les niveaux de négociation et le chapitre consacré à la négociation permanente est particulièrement remarquable.

Cet ouvrage sera utile aux lecteurs canadiens pour mieux connaître le régime français de relations professionnelles. Ceux qui préconisent chez nous la négociation de branche (qu'ils désignent souvent sous le nom de négociation collective) tireront sûrement profit à le lire.

\section{Gérard DION}

\section{Les Mémoires d'Alfred Charpentier} (Cinquante ans de vie ouvrière). Québec, Les Presses de l'Université Laval, 1971, $540 \mathrm{pp}$.

Alfred Charpentier a tenu une place importante dans l'histoire du mouvement syndical au Québec. Ce n'est pas en vain qu'il a intitulé Cinquante ans d'action ouvrière cet ouvrage considérable.

Il faut, au point de départ, se reporter vers la fin du XIXe siècle. Alfred Charpentier naît et grandit dans une famille essentiellement ouvrière. Son père est briqueteur. Il le sera lui-même pendant un certain nombre d'années. Dès l'âge de treize ans et demie, il commence l'apprentissage du métier et, dès cette époque, il s'initie, entraîné par son père, à l'action ouvrière.

Dès ses années d'adolescence et de jeunesse, le jeune Charpentier goûte aux dures conditions de la vie ouvrière: chômage, grèves, faillite de l'entreprise paternelle, maladies familiales. Il n'hésite pas à écrire : "La gêne s'introduisit donc dans notre famille pour de longues années à venir \$.

Charpentier a naturellement quitté l'école de bonne heure pour venir au secours des siens. Mais il n'a jamais renoncé à l'étude. C'est par la lecture surtout qu'il s'est formé, même s'il suivait de près l'activité sociale et politique. Il parle des livres qu'il a lus alors avec le plaisir qu'un jeune d'aujourd'hui mettrait à raconter son premier voyage.

A l'âge de vingt ans, on le retrouve secrétaire d'un syndicat; trois ans plus tard, il en deviendra le président. Déjà, à l'époque, il s'exerce à écrire, envoie des articles aux journaux. 